\title{
DETECTION OF CHLORPYRIFOS PESTICIDE IN VARIOUS WATER SAMPLES USING GOLD NANOPARTICLES
}

\author{
K. Kiran \\ Young Scientist-DST, Department of Environmental Sciences, Sri Venkateshwara University, Tirupathi, Andhra Pradesh, \\ India-517502, kamatamkiran77@gmail.com
}

\begin{abstract}
Gold Nanoparticles successfully applied for detection of Chlorpyrifos pesticide present in various water samples. Structural and morphological studies of Gold Nanoparticles were studied following UV-Visible Spectrophotometer, SEM and HRTEM. Trisodium Citrate has been used as a reducing agent. The author successfully applied Gold Nanoparticles capped with citrate ions for monitoring Chlorpyrifos pesticides up to ppb levels in various water samples.
\end{abstract}

Keywords: Gold Nanoparticles, Chlorpyrifos pesticide, UV-Visible spectrophotometer, SEM, HRTEM, etc.

\section{INTRODUCTION:}

Gold nanoparticles (GNPs) play an imperative role in chemistry and biology by virtue of a large surface-to-volume ratio, quantum confinement, and other unique properties. Gold nanoparticles consist of several kinds of interesting properties $[1,2]$. GNPs, with the diameter of 1-100 $\mathrm{nm}$, have high surface energy and high surface-to-volume ratio to endow with a steady control of a large amount of biomolecules retaining their bioactivity. Moreover, GNPs have a capability to consent fast and direct electron transfer between a wide range of electro active species and electrode materials. Gold nanoparticles may potentially be another useful material for removing contaminants, such as toxic chlorinated organic compounds, pesticides and inorganic mercury, from water.

Gold Nanoparticles and Silver Nanoparticles or silver-silica hybrid nanostructures have been used as biosensor substrates are reported by numerous authors [3-5]. Recent review on Gold Nanoparticles and their biomedical applications shows vast growth in the field of biomedicine [6-9]. Gold Nanoparticle possesses many excellent properties, such as effortless reductive preparation, water solubility, high chemical stability, and significant biocompatibility and affinity [10].

The concentration of Chloropyrifos, cadusafos, diazinon, prothiphos and malathion pesticides in fish samples from different tributaries of the Nile River in Egypt was monitored [11]. Sixteen microbial isolates capable of growing on Dursban as a secondary substrate were isolated from three soil and sewage water samples collected from different localities polluted with pesticides. Biodegradation of organophosphate pesticide chloropyrifos by Egyptian bacterial isolates [12].
Occurrence of 67 pesticides in the Lebanese waters. Chemical analysis was performed by a solid-phase extraction followed by a gas chromatography-mass spectrometry using programmed temperature vaporization injection [13].

In this paper the author developed a novel method using Gold Nanoparticles for the detection of Chlorpyrifos pesticides up to $\mathrm{ppb}$ level present in various environmental water samples.

\section{MATERIALS AND METHODS}

\subsection{Chemicals}

Gold Chloride $\left(\mathrm{HAuCl}_{4} \cdot 3 \mathrm{H}_{2} \mathrm{O}\right)$ was purchased from Research Lab fine chem. Industries, India Limited. Chloropyrifos IUPAC name: $O, O$-diethyl $O$-3, 5, 6-trichloropyridin-2-yl phosphorothioate (Hyderabad chemicals limited, A.P.). Pesticide stock solution was prepared using ethanol as solvent. This solution was diluted in water and used for further experiments. Analytical grade Trisodium citrate, Sodium chloride $(\mathrm{NaCl})$ and other chemicals were purchased from Sigma-aldrich company. Double distilled water was used throughout the experiment.

\subsection{Instrumentation}

Perkin-Elmer model Ultraviolet-Visible Spectrophotomer is used for spectral analysis. Scanning Electron Microscopic (SEM) image was taken using a FEI QUANTA-200 SEM instrument. High Resolution Transmission Electron Microscopy (HRTEM) was carried out using a $300 \mathrm{kV}$ JEOL3011 instrument with a ultra high resolution (UHR) pole piece. 


\subsection{Synthesis of Gold Nanoparticles}

Equal molar ration of Gold chloride $\left(\mathrm{HAuCl}_{4} \cdot 3 \mathrm{H}_{2} \mathrm{O}\right)$ solution is mixed with trisodium citrate following Turkevich method [14]. $5 \mathrm{~mL}$ of $1 \mathrm{M} \mathrm{HAuCl}_{4} \cdot 3 \mathrm{H}_{2} \mathrm{O}$ was diluted with $90 \mathrm{~mL}$ of double distilled water and heated until it begins to boil. To this add $5 \mathrm{~mL}$ of $1 \mathrm{M}$ trisodium citrate solution and continued the reaction until the solution turned wine red. In this reaction trisodium citrate acts as both reducing and capping agent.

\subsection{Stability of Gold Nanoparticles}

To build understandable the reliability of Gold Nanoparticles a Gold Nanoparticles solution has been prepared with various concentrations $(90 \mathrm{ml})$ and was mixed with $10 \mathrm{ml}$ of different concentrations of $\mathrm{NaCl}$ solutions (5M,10M, 25M, 50M) following UV-Visible Spectrophotometric analysis.

\subsection{Detection of Chlorpyrifos Pesticide}

Different concentrations of Chlorpyrifos pesticide standard solutions have been prepared freshly using ethanol as a solvent. Then these solutions were diluted with water to make a final concentration of $2 \mathrm{ml}$. Add $2 \mathrm{ml}$ of Gold Nanoparticles solution to these pesticide solutions and mix these solutions for five minutes. Finally add $1 \mathrm{ml}$ of $10 \mathrm{M} \mathrm{NaCl}$ solution and reflux it for $10 \mathrm{~min}$.

\subsection{SEM and TEM analysis}

Structural and Morphological changes of Gold Nanoparticles capped with citrate ions were done using SEM and HRTEM and shown in Figure 1a \& b.

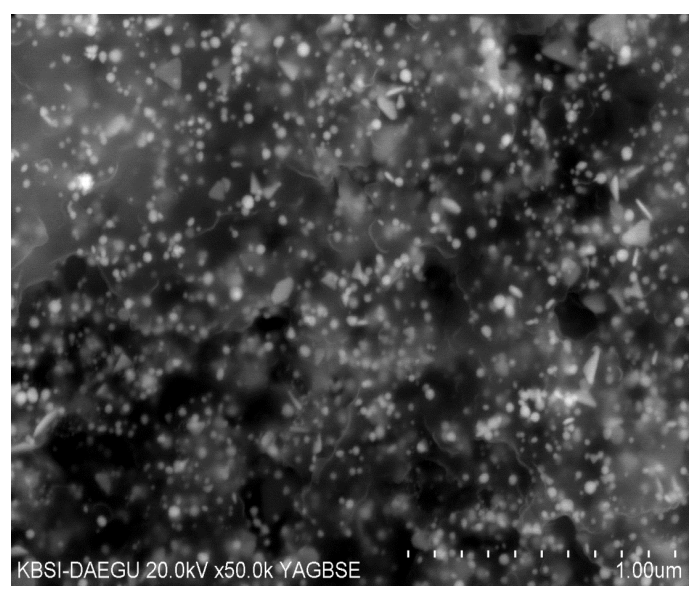

Fig 1 (a) SEM images for Gold Nanoparticles

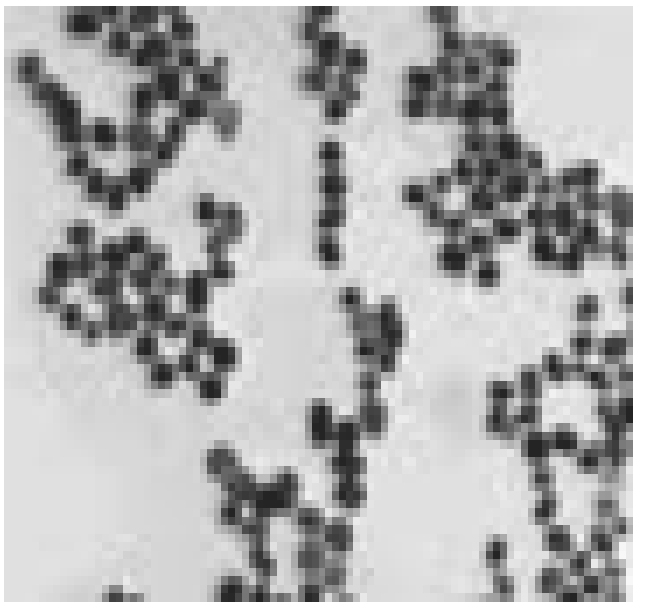

Fig 1(b). HRTEM images for Gold Nanoparticles

\section{RESULTS AND DISCUSSION}

Synthesized Gold Nanoparticles has been known in the solution by the color changing from pale yellow to wine red. The color change can be easily identified by the naked eye. Figure 2 shows photograph of Gold Nanoparticles. It was clearly indicates that citrate ions act as stabilizing agent, capping agent and also it act as reducing agent to convert $\mathrm{Au}^{+3}$ to $\mathrm{Au}^{0}$. In addition, Gold Nanoparticles have a characteristic surface plasma resonance band around 300- $800 \mathrm{~nm}$ and the maximum absorbance was found at $545 \mathrm{~nm}$ which was shown in Figure 3. Temperature also plays important role in reaction mechanism and $50^{\circ} \mathrm{c}$ shows maximum absorbance under controlled conditions.

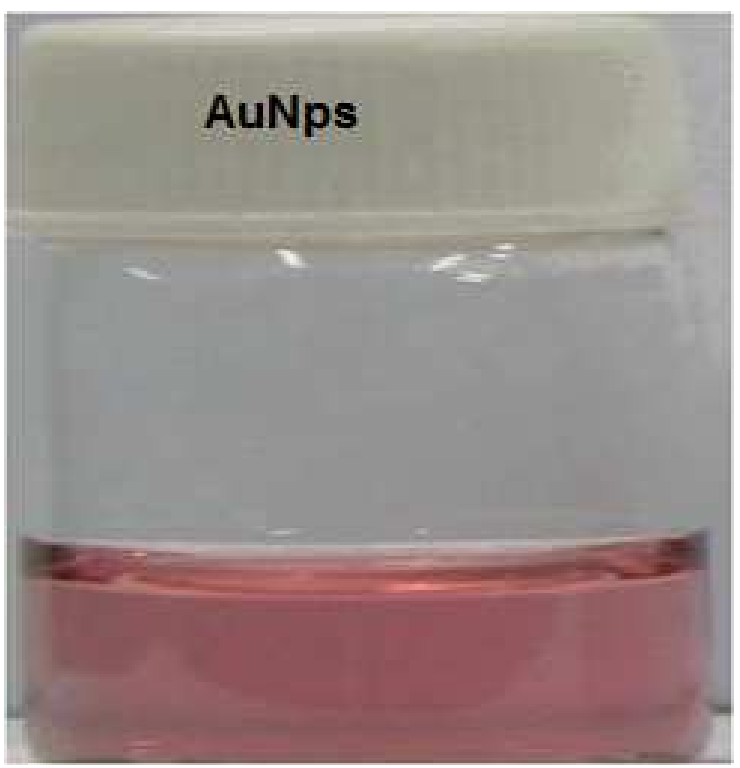

Fig 2 Shows photograph of Gold Nanoparticles 


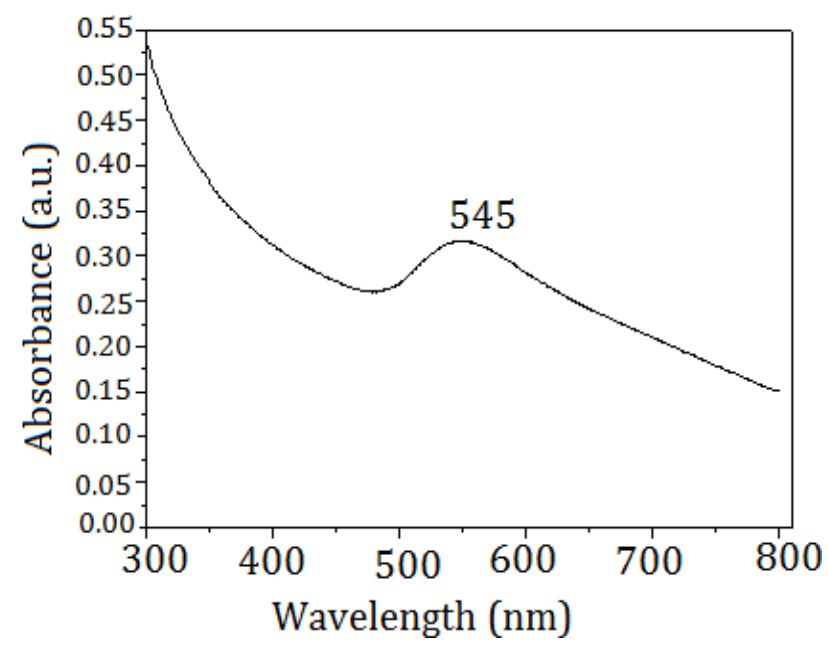

Fig 3 Shows UV-Visible spectra of Gold Nanoparticles

\subsection{Stability}

Citrate ions having negative charges and maintain stability in Gold Nanoparticles solution. Adding of different concentrations of $\mathrm{NaCl}$ solution to that of Gold Nanoparticles increases stability for Gold Nanoparticles and it was clearly observed in UV-Visible Spectrophotometry. The domino effect confirms that maximum stability for Gold Nanoparticles was obtained at $10 \mathrm{M} \mathrm{NaCl}$ concentration.

\subsection{Detection of Chlorpyrifos pesticide}

Under optimum conditions, Synthesized Gold Nanoparticles was used successfully for the determination of chlorpyrifos pesticide in various water samples. Gold Nanoparticles was mixed with different concentrations of chlorpyrifos pesticide shows no color due to absence of $\mathrm{NaCl}$ solution and presence of citrate ions which act as stabilizer. By the addition of $10 \mathrm{M}$ $\mathrm{NaCl}$ solution to the mixture, the color was changed from wine red to purple blue was shown in Figure 4 . The appearance of purple blue color indicates that Gold Nanoparticles capped with citrate ions holds chlorpyrifos pesticides in presence of $\mathrm{NaCl}$. After 5 minutes the color slowly turns to purple due to pesticide concentration. Citrate ions act as reducing agent to synthesize Gold Nanoparticles from Gold Chloride $\left(\mathrm{HAuCl}_{4}\right)$, which is wine red in color. Tri sodium Citrate contains many negative ions which helps to reduce $\mathrm{Au}^{+3}$ to $\mathrm{Au}^{0}$, and also because of high negative charges of citrate also acts as stabilizer and maintain wine red color for Gold Nanoparticles even pesticide solution has been added. Whenever $\mathrm{NaCl}$ solution was added, then the Gold Nanoparticles solution changed its color from wine red to blue depending on chlorpyrifos concentration.

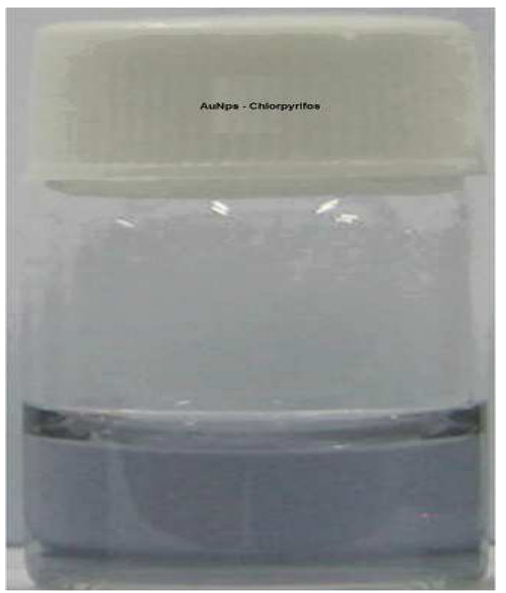

Fig 4 Shows Gold Nanoparticles with chlorpyrifos pesticide

\subsection{Analysis of Water samples}

Gold Nanoparticles complexation with chlorpyrifos pesticides in presence of $\mathrm{NaCl}$ was studied by using real water samples. These samples were collected from Renigunta industrial area, Andhra Pradesh, INDIA. These samples were spiked with the chlorpyrifos pesticide and Spectrophotometric determination was done using $60 \mathrm{ppb}$ chlorpyrifos.

\section{CONCLUSIONS}

Gold Nanoparticles capped with citrate group shows good complexation with chlorpyrifos pesticides upto ppb levels. Ultra Violent Visible Spectrophotometry. HRTEM and Scanned Electron Microscopic analysis shows clear mechanism of complexation of Gold Nanoparticles with chlorpyrifos pesticide residues. This was extending to monitor the chlorpyrifos pesticide residues in real samples also. Further study is required to monitor the pesticides in real samples up to ppb level.

\section{ACKNOWLEDGEMENTS}

I Thanks to Umesh Kumar Sharma- Scientist-D, Department of Science and Technology, who supports me to sanctioned project under fast track young scientist scheme to work continuously on Gold nanoparticles.

\section{REFERENCES}

[1]. J. Wang, R. Polsky and D. Xu, Silver-Enhanced Colloidal Gold Electrochemical Striping Detection of DNA Hybridization Langmuir, 2001, 17, 5739-5743.

[2]. J. Wang, D. Xu and R. Polsky, Magnetically Induced Electrical DNA Detection" J Am Chem Soc, 2002, 124, 42084212.

[3]. Y. Xiao, F. Patolsky, E. Katz, J.F. Hainfeld and I. Willner, 'Plugging into enzymes- Nanowiring of redox-enzymes by a gold nanoparticle, Science, 2003, 299, 1877-1883. 
[4]. M. Schierhorn, S.J. Lee, S.W. Boettcher, G.D. Stucky and M. Moskovits, Metal-Silica hybrid nanostructures for surfaceenhanced raman spectroscopy, Advanced Materials, 2006, 18, 2829-2834.

[5]. H. Cai, Y. Xu, N. Zhu, P. He and Y. Fang, An electrochemical DNA hybridization detection assay based on a silver nanoparticle label. Analyst, 2002, 127,803.

[6]. J.B. Delehanty, K. Boeneman, C.E. Bradburne, K. Robertson, J.E.Bongard and I.L.Medintz, "Peptides for specific intracellular delivery and targeting of nanoparticles: Implications for developing nanoparticle-mediated drug delivery. Ther. Deliv. 2010, 1, 411-433.

[7]. D.A.Giljohann, D.S. Seferos, W.L. Daniel, M.D. Massich, P.C. Patel and C.A. Mirkin, Gold nanoparticles for biology and medicine. Angew. Chem. Int. Ed. 2010, 49, 3280-3294.

[8]. R.A.Petros and J.M. DeSimone, Strategies in the design of nanoparticles for therapeutic applications. Nat. Rev. Drug Discovery 2010, 9, 615-627.

[9]. J. Shi, A.R. Votruba, O.C. Farokhzad, and R. Langer, Nanotechnology in drug delivery and tissue engineering: From discovery to applications. Nano Lett. 2010, 10, 3223-3230.

[10]. M. C. Daniel, and D. Astruc, Gold nanoparticles: assembly, supramolecular chemistry, quantum-size-related properties, and applications toward biology, catalysis, and nanotechnology, Chem. Rev. 104 (2004)293-346.

[11]. F. Malhat, and I.Nasr. Organophosphorus pesticides residues in fish samples from the River Nile tributaries in Egypt. Bull Environ Contam Toxicol. 2011, 87(6):689-92.

[12]. R.A. Bayoumi, E.Mohamed, S.Louboudy, and A. Hendawy. Biodegradation of organophosphate pesticide chloropyrifos by Egyptian bacterial isolates, Commun Agric Appl Biol Sci. 2009 74(1), 177-95.

[13]. A.Kouzayha, A. Al Ashi, R. Al Akoum, M. Al Iskandarani, H.Budzinski, and F.Jaber. occurrence of pesticide residues in Lebanon's water resources, Bull Environ Contam Toxicol. 2013, 91(5), 503-9.

[14]. B.V. Enustun, and J. Turkevich, Coagulation of colloidal gold. J. Am.Chem. Soc. 1963, 85, 3317-3328. 